\title{
Research advances on flotillins
}

\author{
Feng Zhao', Jie Zhang ${ }^{1}$, Yong-Sheng Liư ${ }^{1 *}$ Li Li ${ }^{2}$ and Ya-Li He ${ }^{3}$
}

\begin{abstract}
The proteins of flotillin-1 and flotillin-2 were originally discovered in axon regeneration of goldfish retinal ganglion cells. They are generally used as marker proteins of lipid rafts and considered to be scaffolding proteins of lipid microdomains. Although they are ubiquitously expressed and well-conserved from fly to man, their exact functions remain controversial. In this review, we summarize the structure of flotillins and some functions of them, such as regulating axon regeneration, endocytosis, $T$ cell activation, insulin signaling, membrane protein recruitment, roles in the progression of some diseases and so on.
\end{abstract}

Keywords: Flotillin-1, Flotillin-2, Lipid raft, Signal transduction, Prion protein, GPI-anchored proteins

\section{Introduction}

Lipid rafts, which act as signaling and sorting platforms for numerous molecules, are stero- and sphingolipidenriched small microdomains of cell membrane $[1,2]$. Flotillins, also called reggies, are considered to be scaffolding proteins of lipid rafts and are generally used as marker proteins of lipid microdomains. There are two homologous members in flotillin proteins family, flotillin- 1 and flotillin-2. These proteins were originally discovered as regeneration molecules upregulated in regenerating axons of goldsish retinal ganglion cells after lesion of the optic nerve and thus named reggies for regeneration [3]. Then, Bickel et al. found that they were insoluble in TritonX-100 and float after sucrose density centrifugation, and hence named flotillins [4]. Actually, reggie-1 corresponds to flotillin-2, while reggie-2 corresponds to flotillin-1.

Flotillins are evolutionarily well-conserved and ubiquitously expressed from fly to man [5]. The identity of amino acid sequence of flotillins among vertebrate is about $90 \%$, and the identity between vertebrate and invertebrates is about 64\% [6]. Flotillin-2 has a wide distribution in different tissues, while the expression of flotillin-1 seems to be more restricted in mammalian [7]. Flotillin-1 is expressed most abundantly in brain, heart, lung, placenta [8], and in hematopoietic cells [9]. The expression analysis of flotillin-2 in mouse and human

\footnotetext{
* Correspondence: liuyongshengvip8@163.com

${ }^{1}$ State Key Laboratory of Veterinary Etiological Biology, Lanzhou Veterinary Research Institute, Chinese Academy of Agricultural Sciences. Lanzhou, 730046, Gansu, P.R. China

Full list of author information is available at the end of the article
}

tissues by quantitative PCR suggested that it could express in all tissues. In some cell types, flotillins also localize in endosomal compartments, phagosomes, Golgi compartment and even exosomes [10-13]. Unexpectedly, flotillin-1 can colocalize with PTOV1 in the nucleus [14]. The human flotillin-1 gene is located on chromosome $6 \mathrm{p} 21.3$, whereas the human flotillin-2 gene is located on chromosome 17q11-12. Both genes are single-copy gene consisting of 13 and 11 exons, respectively, and both code a protein of $47 \mathrm{kDa}[8,15]$.

\section{Structure of flotillins}

Flotillins are considered to belong to the SPFH (stomatin, prohibitin, flotillin, HflK/C) protein family, which share a novel homology at their N-terminus region [16]. Moreover, their C-terminal region has several short repeat motifs called flotillin repeats, which are important for the formation of homo- and hetero-oligomers [17]. Flotillin proteins do not traverse the membrane but associate with some other proteins resided at the other side of them [18]. Thus, a transmembrane protein may exist which mediate the association of them. Flotillin-1 contains a palmitoylation site in Cys34, which is considered to be essential for the plasma membrane localization of it in kidney cells [19]. However, the palmitoylation site in Cys34 seems to be not critical on the localization of flotillin-1 in adipocytes [20]. Two hydrophobic stretches (amino acids 10-36 and 134-151) in flotillin-1 can facilitate its membrane association, especially the first one is more important [20]. Thus, the membrane targeting signals of flotillin-1 may be dependent on cell types. Unlike flotillin-1, flotillin-2 is 
associated with membranes through myristoylation in Gly2 and manifold palmitoylation (Cys4, Cys19 and Cys20) [21]. The stimulation of cells by epidermal growth factor (EGF) leads to a Tyr163-dependent translocation of flotillin-2 from the plasma membrane into endosomes [22].

Both flotillins are palmitoylated in the hetero-oligomers of flotillin-1 and flotillin-2, and the fully acylated hetero-oligomers on a cytoplasmis vesicle ultimately fuses with the plasma membrane [13]. The fully acylated hetero-oligomers can be phosphorylated by Fyn, then they were endocytosed at the plasma membrane $[23,24]$. They can be transferred from a early endosome to the late endosomal compartment [24,25]. Flotillins were originally considered to reside in plasma membrane caveolae and form hetero-oligomers with caveolar proteins [7]. This view was contradictory to the notion that flotillins are localized to non-caveolar microdomains $[21,26]$.

\section{Functions of flotillins proteins}

Although flotillins are evolutionarily conserved and universally expressed, their functions have remained controversial. Here, we review the recent findings providing novel insights into the function of flotillins. Both flotillins are preferentially associated with each other in hetero-oligomeric complexes, forms membrane microdomains that participate many cellular activities. The expression of one is regulated by the other, and reduction in one causes the reduction of the other [23]. They are involved in axon regeneration and neuronal differentiation, endocytosis, T-lymphocyte activation, membrane protein recruitment and so on. Furthermore, flotillin-1 also plays an important role in insulin signaling and cell proliferation, while flotillin-2 may influence tumor progression.

\section{Axon regeneration and neuronal differentiation}

The flotillin proteins were originally discovered in neurons during axon regenetation, implying that they may be involved in regeneration of axon. During axon regeneration, flotillins were upregulated in retinal ganglion cells (RGC) of fish [3]. Munderloh et al. found that downregulation of flotillins triggered a clear reduction (up to $70 \%$ ) of the number of regenerating axon in zebrafish, indicating that flotillins are indeed necessary for axon regeneration [27]. Furthermore, they are upregulated in mammalian retinal ganglion cells [28]. The expression levels of flotillins were downregulated in mammalian hippocampal neurons, causing the neurons failed to differentiate [29]. The knockdown of flotillins by flotillin-specific siRNAs restrained the axon regeneration and differentiation in hippocampal and N2a neurons [27]. Flotillins were upregulated during neutrophilic differentiation of HL-60 cells [30].
Additionally, Langhorst reported that expression of a trans-negative flotillin-2 deletion mutant, which interferred the oligomerization of flotillin, could inhibit insulin-like growth factor (IGF)-induced neurite outgrowth in N2a cells and impair differentiation of primary rat hippocampal neurons in vitro [25]. Taken together, flotillins clearly regulate regeneration and neuronal differentiation.

\section{Endocytosis}

The association between flotillins and Src family kinase Fyn has been reported by several studies. In adipocytes, $\mathrm{T}$ lymphocytes and neurons, flotillins may interact with Fyn, indicating that flotillins have important roles in the formation of signal transduction centers $[13,20]$. Epidermal growth factor (EGF)-induced endocytosis depended on the phosphorylation of tyrosine residues on Tyr-160 in flotillin-1 and Tyr-163 in flotillin-2 by Fyn, and mutation of these two residues to phenylalanine prevents Fyn-induced flotillin internalisation [24,22]. Aït-Slimane found that the down-expression of flotillin-2 inhibited endocytosis of glycosyl phosphatidylinositol (GPI)anchored proteins in hepatic cells, suggesting that endocytosis of GPI-anchored proteins depend on a clathrinand flotillin-dependent pathway [31]. Cremona et al. reported that the flotillin-1-enriched membrane microdomains were required in protein kinase C (PKC)-triggered dopamine transporter (DAT) endocytosis [32]. Liang et al. suggested that flotillins play an important role in Niemann-Pick C1-like 1 (NPC1L1)-mediated cholesterol uptake. Knockdown of flotillins notablely attenuated the uptake of cholesterol and endocytosis of NPC1L1 [33].

\section{Insulin signaling}

The exact role of flotillin-1 has been characterized in molecular detail in case of insulin signaling. Baumann et al. found that flotillin-1 formed a ternary complex with $\mathrm{Cb} 1$ and $\mathrm{Cb} 1$-associated protein (CAP) by yeast twohybrid screening [34]. This complex was recruited into lipid rafts after insulin stimulation through interaction between the first hydrophobic domain of flotillin-1 and the SoHo (sorbin homology) domain of CAP [20,34]. Prohibiting this step will block the uptake of glucose by the glucose transporter type-4 GLUT4 [34]. However, some studies suggested that the role of flotillin-1 in insulin signaling might be independent of the interaction with CAP $[35,36]$. The phosphorylation of Cb1 recruites the CrkII-C3G complex to lipid rafts, then C3G specifically activates the small guanosine 5'-triphosphate-hydrolyzing enzyme (GTPase) TC10 [37]. The activation of TC10 is crucial for insulin-stimulated glucose uptake and translocation of GLUT4 from internal storage sites to the cell surface [37]. Fecchi et al. 
demonstrated that GLUT4 localizes in perinuclear regions with flotillin-1 in skeletal muscle cells. GLUT4 moves to the sarcolemma where uptake case of glucose occurs when insulin stimulation. However, if flotillin-1based domains are interferred by a cholesterol-sequestering agent, insulin can not stimulate GLUT4 translocation and uptake of glucose [38].

\section{Function in cell proliferation}

As stated before, flotillin-1 can translocate into the nucleus. Flotillin-1 interacts with the mitogenic protein PTOV1, which shuttles between the nucleus and the cytoplasm in PC-3 and COS-7 cells. Flotillin-1 entered the nucleus following PTOV1 during S phase[14]. Depletion of either flotillin-1 or PTOV1 both could inhibit cell proliferation observably, while over-expression of either protein strongly induced proliferation [39]. Gómez et al. reported that flotillin-1 was crucial for maintaining the levels of the mitotic regulator Aurora B, and interacted with Aurora B directly through its SPFH domain. Flotillin-1 increased Aurora B levels and activity when translocated into the nucleus, while depletion of flotillin-1 downregulated the levels and activity of Aurora B [40].

\section{Platform function for signaling in T cells}

In $\mathrm{T}$ cells, flotillin microdomains are pre-clustered at one pole of the cell to form flotillin cap, which is important for $\mathrm{T}$ cell activation [9]. When $\mathrm{T}$ cell was stimulated, signaling molecules, including Thy-1, TCR/CD3, Fyn, lck and LAT, are recruited to the stable flotillin caps [41]. Antibody crosslinking of GPI-anchored proteins Thy-1 or $\operatorname{PrP}^{\mathrm{c}}$ (cellular prion protein) also leads to selective association with the cap [42]. These signaling molecules are involved in the activation of $\mathrm{T}$ cell. The trans-negative flotillin-2 deletion mutant, which interferes with assembly of flotillin cap, blocked raft polarization and macrodomain formation after $\mathrm{T}$ cell activation and led to the incorrect positioning of the guanine nucleotide exchange factor Vav, resulting in defects in cytosbeletal reorganization [41].

$\operatorname{PrP}^{\mathrm{c}}$, which is activated in the flotillin cap, induces the phosphorylation of the mitogen-activated protein (MAP) kinase ERK1/2 and elicits a distinct $\mathrm{Ca}^{2+}$ signal resulting in recruitment of the major $\mathrm{T}$ cell receptor component $\mathrm{CD} 3$ although the recruitment is not sufficient [43]. The recruitment of $\mathrm{T}$ cell receptor encompasses communication with Src tyrosine kinases (Fyn, Lck, Src), Rho-GTPase and the signaling molecule Vav [41]. Therefore, the microdomains of flotillin provide a platform for signaling in $\mathrm{T}$ cells.

\section{Role in tumor progression}

Hazarika et al. found that both flotillin-2 protein and mRNA were increased in tumorigenic and metastatic melanoma cell lines in vitro. SB2 melanoma cells altered to highly tumorigenic and metastatic in nude mice after transfection of flotillin-2. These cells also proliferated fast in the absence of serum, and thrombin enhanced their migration. Furthermore, the expression of protease activated receptor 1 (PAR-1) mRNA increased in these cell [44]. PAR-1 is a transmembrane, G-protein-coupled receptor involved in melanoma progression. In contrast, depletion of flotillin-2 by means of specific small-interfering RNAs made substantially less flotillin-2 and PAR1 mRNA [44]. Thus, flotillin-2 may play an important role in affecting tumor progression through interacting with PAR-1.

\section{Association with other proteins}

Kato et al. suggested that flotillin-1 was a crucial molecule in IgE receptor-mediated mast cell activation, and involved in the activation of Lyn [45]. The interaction between flotillin-1 with CAP, Vinexin $\alpha$ and ArgBP2, respectively, all of which are members of the SoHo family, indicates that flotillin-1 related to the organization of the actin cytoskeleton [46]. The interaction between flotillin-1 and neuroglobin ( $\mathrm{Ngb}$ ) identified by GST-pulldown assays implies that flotillin-1 might recruit Ngb to lipid rafts as a means of preventing neuronal death [47]. Flotillin-2 interacts with F-actin through its SPFH domain and regulates its lateral mobility at the plasma membrane [48]. Flotillin-2 was found to interact with kinesin KIF9 and knockdown of flotillins reduced matrix degradation by pososomes, which suggest that flotillin and KIF9 proteins can regulate matrix degradation by macrophage podosomes [49]. Flotillin microdomains associate with several cytoskeletal proteins, particularly myosin Ila and spectrin, suggesting that flotillins play an important roles during neutrophil migration in uropod formation and in the regulation of myosin Ila [50]. The N-terminal portion of flotillins is crucial for its interaction with the heterotrimeric $\mathrm{G}$ protein $\alpha$ q subunit (Gaq). The knockdown of flotillins, especially flotillin-2, damped the UTP-induced activation of p38 mitogen-activated protein kinase (MAPK). The activation of p38 MAPK was inhibited by the Src family kinases, suggesting that flotillins modulated Gq-induced p38 MAPK activation [51].

\section{Flotillins in neurodegenerative diseases}

Some studies suggested that flotillins play a role in the pathogenesis of neurodegenerative diseases such as prion diseases (BSE, scrapie and CJD et al.), Parkinson's and Alzheimer's diseases (AD). Prion diseases are caused by misfolding of cellular prion protein $\left(\operatorname{PrP}^{c}\right)$. Stuermer et al. shown that $\operatorname{PrP}^{\mathrm{c}}$ was closely associated with flotillins at the plasma membrane in lymphocytes. Moreover, cross-linking of $\operatorname{PrP}^{\mathrm{c}}$ resulted in its clustering in the region of the preformed flotillin cap [42]. Flotillins were 
also found in lipid-rich vesicles from Jurkat $\mathrm{T}$ cells together with $\operatorname{PrP}^{\mathrm{c}}$ [52]. Furthermore, scrapie prion protein $\left(\mathrm{PrP}^{\mathrm{Sc}}\right)$ is localized in flotillin-1 positive late endosomes in the central nervous system cells [53]. Thus, clustering of $\operatorname{PrP}$ may contribute to the spreading of prion diseases. The expression of flotillin-1 was upregulation in the substantia nigra of Parkinson's patients [54]. Rajendran et al. reported that cellular amyloid beta-protein $(A \beta)$, which is a pathological hallmark of $\mathrm{AD}$, accumulated in flotillin-1 positive endocytic vesicles. Additionally, flotillin-1 associated with extracellular $A \beta$ plaques in AD patient brain sections [55]. Sratins, which strongly reduced the $A \beta$ load by modulating the processing of the amyloid beta precursor protein and reduced the prevalence of $\mathrm{AD}$, also reduced the expression of flotillin-1 [56]. These may indicate an association of flotillin-1 with AD. Taken together, these studies indicated that flotillins may participate in the progression of some neurodegenerative diseases.

\section{Conclusions}

No matter what the details of the functions of flotillins be, it is obvious that flotillins do not simply function as scaffolding proteins for lipid rafts but active signaling partners taking part in various vital cell processes. It involves in axon regeneration and neuronal differentiation, endocytosis, T-lymphocyte activation, etc. Moreover, a hypothesis suggests that flotillins are involved in the recruitment of membrane and specific membrane proteins to specific regions or domains of the cell [29]. Some reports shown that flotillins are involved in the recruitment of the GLUT4 from internal stores to the plasma membrane in adipocytes $[34,57]$, in the recruitment of cadherin to the cell membrane of embryonic and epithelial cells, in the recruitment of the TCR to the T cell cap in lymphocytes, and in the recruitment of integrins to focal adhesions [58]. This function is required in all cells which explains why flotillins are expressed in many or all cells in invertebrates and vertebrates. The microdomains of flotillins may facilitate the assembly of special cell surface proteins and signaling complexes at the plasma membrane in a cell type specific manner, hence causing the internal proteins recruiting to the membrane domains and also involving some signaling processes. Now that flotillins are ubiquitously expressed in so many cells, they are surely involved in some more functions excepting we have found. So there is a wide prospect about the research of flotillins. However, the exact functions of flotillins remain controversial and further experiment must be supported in many aspects.

\section{Abbreviations}

PTOV1: prostate tumor overexpressed gene 1 protein; EGF: epidermal growth factor; RGC: retinal ganglion cells; IGF: insulin-like growth factor; GPI: glycosyl phosphatidylinositol; PKC: protein kinase C; DAT: dopamine transporter; NPC1L1: Niemann-Pick C1-like 1; CAP: Cb1-associated protein; SoHo: sorbin homology; GLUT4: glucose transporter type-4; Crk: CT10-related kinase; GTPase: guanosine 5'-triphosphate-hydrolyzing enzyme; TCR: T cell receptor; LAT: linker of activated T cells; PrPc: cellular prion protein; MAP: mitogen-activated protein; ERK1/2: extracellular regulated kinases 1/2; PAR-1: protease activated receptor 1; Ngb: neuroglobin; Gaq: G protein a q subunit; MAPK: mitogen-activated protein kinase; BSE: bovine spongiform encephalopathy; CJD: Creutzfeldt-Jakob disease; AD: Alzheimer's diseases; $\operatorname{PrP}^{S C}$ : scrapie prion protein; $A \beta$ : amyloid beta-protein.

\section{Acknowledgements}

This work was supported in parts by grants from National Natural Science Foundation of China General Projects (No.30671563 and No.31072143).

\section{Author details}

'State Key Laboratory of Veterinary Etiological Biology, Lanzhou Veterinary Research Institute, Chinese Academy of Agricultural Sciences. Lanzhou, 730046, Gansu, P.R. China. ${ }^{2}$ The People's Government of Huaikou Town in Jintang County of Chengdu City, Chengdu, 610404, Sichuan, P.R. China. ${ }^{3}$ School of Public Health, Lanzhou university, Lanzhou, 730000, Gansu, P.R. China.

\section{Authors' contributions}

FZ, JZ and LL conceived of the study and drafted the manuscript; YLH helped to draft the manuscript. YSL supervised the research and helped to draft the manuscript. All authors read and approved the final manuscript.

\section{Authors' information}

FZ: Qualification: Bachelor's degree. Current position: Post Graduate of Lanzhou Veterinary Research Institute, Chinese Academy of Agricultural Sciences (CAAS).

JZ: Qualification: Doctor's degree. Current position: As a researcher in the Department of Virology, Lanzhou Veterinary Research Institute, CAAS.

YSL: Qualification: Doctor's degree. Current position: As a associate professor in the Department of Virology, Lanzhou Veterinary Research Institute, CAAS. LL: Qualification: Bachelor's degree. Current position: As a College-Graduate Village Official in the People's Government of Huaikou Town in Jintang County of Chengdu City

YLH: Qualification: Bachelor's degree. Current position: Post Graduate of School of Public Health, Lanzhou university.

\section{Competing interests}

The authors declare that they have no competing interests.

Received: 17 August 2011 Accepted: 25 October 2011 Published: 25 October 2011

\section{References}

1. Pike LJ: Rafts defined: a report on the Keystone Symposium on Lipid Rafts and Cell Function. J Lipid Res 2006, 47:1597-1598.

2. Allen JA, Halverson-Tamboli RA, Rasenick MM: Lipid raft microdomains and neurotransmitter signaling. Nat Rev Neurosci 2007, 8:128-140.

3. Schulte T, Paschke KA, Laessing U, Lottspeich F, Stuermer CA: Reggie-1 and reggie-2, two cell surface proteins expressed by retinal ganglion cells during axon regeneration. Development 1997, 124:577-587.

4. Bickel PE, Scherer PE, Schnitzer JE, Oh P, Lisanti MP, Lodish HF: Flotillin and epidermal surface antigen define a new family of caveolae-associated integral membrane proteins. J Biol Chem 1997, 272(21):13793-13802.

5. Malaga-Trillo E, Laessing U, Lang DM, Meyer A, Stuermer CA: Evolution of duplicated reggie genes in zebrafish and goldfish. J Mol Evol 2002, 54(2):235-245.

6. Rivera-Milla E, Stuermer CA, Malaga-Trillo E: Ancient origin of reggie (flotillin), reggie-like, and other lipid-raft proteins: convergent evolution of the SPFH domain. Cell Mol Life Sci 2006, 63(3):343-357.

7. Volonte D, Galbiati F, Li S, Nishiyama K, Okamoto T, Lisanti MP: Flotillins/ cavatellins are differentially expressed in cells and tissues and form a hetero-oligomeric complex with caveolins in vivo. Characterization and epitope-mapping of a novel flotillin-1 monoclonal antibody probe. J Biol Chem 1999, 274(18):12702-12709. 
8. Edgar AJ, Polak JM: Flotillin-l:gene structure:cDNA cloning from human lung and the identification of alternative polyadenylation signals. Int J Biochem Cell Biol 2001, 33(1):53-64.

9. Rajendran L, Masilamani M, Solomon S, Tikkanen R, Stuermer CA, Plattner H, Illges $\mathrm{H}$ : Asymmetric localization of flotillins/reggies in preassembled platforms confers inherent polarity to hematopoietic cells. Proc Natl Acad Sci USA 2003, 100(14):8241-8246.

10. de Gassart A, Geminard C, Fevrier B, Raposo G, Vidal M: Lipid raftassociated protein sorting in exosomes. Blood 2003, 102(13):4336-4344.

11. Dermine JF, Duclos S, Garin J, St-Louis F, Rea S, Parton RG, Desjardins M: Flotillin-1-enriched lipid raft domains accumulate on maturing phagosomes. J Biol Chem 2001, 276(21):18507-18512.

12. Gkantiragas I, Brugger B, Stuven E, Kaloyanova D, Li XY, Lohr K, Lottspeich F, Wieland FT, Helms JB: Sphingomyelin-enriched microdomains at the Golgi complex. Mol Biol Cell 2001, 12(6):1819-1833.

13. Stuermer CA, Lang DM, Kirsch F, Wiechers M, Deininger SO, Plattner H: Glycosylphosphatidyl inositol-anchored proteins and fyn kinase assemble in noncaveolar plasma membrane microdomains defined by reggie-1 and -2. Mol Biol Cell 2001, 12(10):3031-3045.

14. Santamaria A, Fernandez PL, Farre X, Benedit P, Reventos J, Morote J, Paciucci R, Thomson TM: PTOV-1, a novel protein overexpressed in prostate cancer, shuttles between the cytoplasm and the nucleus and promotes entry into the $S$ phase of the cell division cycle. Am J Pathol 2003, 162(3):897-905

15. Schroeder WT, Siciliano MJ, Stewart-Galetka SL, Duviv M: The human gene for an epidermal surface antigen (M17S1) is located at 17q11-12. Genomics 1991, 11(2):481-482.

16. Tavernarakis N, Driscoll M, Kyrides NC: The SPFH domain: implicated in regulating targeted protein turnover in stomatins and other membraneassociated proteins. Trends Biochem Sci 1999, 24(11):425-427.

17. Solis GP, Hoegg M, Munderloh C, Rivera-Milla E, Stuermer CAO: Rules for reggie oligomerization and stabilization. Biochem J 2007, 403:313-322.

18. Bauer $M$, Pelkmans $L: A$ new paradigm for membrane-organizing and -shaping scaffolds, FEBS Lett. 2006, 580:5559-5564.

19. Morrow IC, Rea S, Martin S, Prior IA, Prohaska R, Hancock JF, James DE, Parton RG: Flotillin-1/reggie-2 traffics to surface raft domains via a novel Golgiindependent pathway. Identification of a novel membrane targeting domain and a role for palmitoylation. J Biol Chem 2002, 277(50):48834-48841.

20. Liu J, Deyoung SM, Zhang M, Dold LH, Saltiel AR: The stomatin/prohibitin/ flotillin/HflK/C domain of flotillin-1 contains distinct sequences that direct plasma membrane localization and protein interactions in $3 \mathrm{~T} 3-\mathrm{L} 1 \mathrm{a}$ dipocytes. J Biol Chem 2005, 280(16):16125-16134.

21. Neumann-Giesen C, Falkenbach B, Beicht P, Claasen S, Luers G, Stuermer CA, Herzog V, Tikkanen R: Membrane and raft association of reggie-1/flotillin-2: role of myristoylation, palmitoylation and oligomerization and induction of filopodia by overexpression. Biochem J 2004, 378(Pt2):509-518.

22. Neumann-Giesen C, Fernow I, Amaddii M, Tikkanen R: Role of EGF-induced tyrosine phosphorylation of reggie-1/flotillin-2 in cell spreading and signaling to the actin cytoskeleton. J Cell Sci 2007, 120(Pt3):395-406.

23. Babuke T, Ruonala M, Meister M, Amaddii M, Genzler C, Esposito A, Tikkanen R: Hetero-oligomerization of reggie-1/flotillin-2 and reggie-2/ flotillin-1 is required for their endocytosis. Cell Signal 2009, 21(8):1287-1297.

24. Riento K, Frick M, Schafer I, Nichol BJ: Endocytosis of flotillin-1 and flotillin-2 is regulated by Fyn kinase. J Cell Sci 2009, 122(Pt7):912-918.

25. Langhorst MF, Reuter A, Jaeger FA, Wippich FM, Luxenhofer G, Plattner $H$, Stuermer CA: Trafficking of the microdomain scaffolding protein reggie1/flotillin-2. Eur J Cell Biol 2008, 87(4):211-226.

26. Fernow I, Icking A, Tikkanen R: Reggie-1 and reggie-2 localize in noncaveolar rafts in epithelial cells: cellular localization is not dependent on the expression of caveolin proteins. Eur J Cell Biol 2007, 86(6):345-352.

27. Munderloh C, Solis GP, Bodrikov V, Jaeger FA, Wiechers M, Málaga-Trillo E, Stuermer CA: Reggies/flotillins regulate retinal axon regeneration in the zebrafish optic nerve and signal transduction in N2a cells. J Neurosci 2009, 29(20):6607-6615.

28. Lang DM, Lommel S, Jung M, Ankerhold R, Petrausch B, Laessing U, Wiechers MF, Plattner $\mathrm{H}$, Stuermer CA: Identification of reggie-1 and reggie-2 as plasmamembrane-associated proteins which cocluster with activated GPI-anchored cell adhesion molecules in non-caveolar micropatches in neurons. J Neurobio/ 1998, 37(4):502-523.

29. Stuermer CA: The reggie/flotillin connection to growth. Trends Cell Biol 2009, 20(1):6-13.

30. Yanagida M, Nakayama H, Yoshizaki F, Fujimura T, Takamori K, Ogawa $H$, Iwabuchi K: Proteomic analysis of plasma membrane lipid rafts of $\mathrm{HL}-60$ cells. Proteomics 2007, 7(14):2398-2409.

31. Ait-Slimane T, Galmes R, Trugnan G, Maurice M: Basolateral Internalization of GPI-anchored Proteins Occurs via a Clathrin-independent Flotillindependent Pathway in Polarized Hepatic Cells. Mol Biol Cell 2009, 20(17):3792-3800.

32. Cremona ML, Matthies HJ, Pau K, Bowton E, Speed N, Lute BJ, Anderson M, Sen N, Robertson SD, Vaughan RA, Rothman JE, Galli A, Javitch JA, Yamamoto A: Flotillin-1 is essential for PKC-triggered endocytosis and membrane microdomain localization of DAT. Nature Neuroscience 2011, 14(4):469-477.

33. Ge L, Qi W, Wang LJ, Miao HH, Qu YX, Li BL, Song BL: Flotillins play an essential role in Niemann-Pick C1-like 1-mediated cholesterol uptake. Proc Natl Acad Sci USA 2011, 108:551-556.

34. Baumann CA, Ribon V, Kanzaki M, Thurmond DC, Mora S, Shigematsu S, Bickel BE, Pessin JE, Saltiel AR: CAP defines a second signalling pathway required for insulin-stimulated glucose transport. Nature 2000, 407(6801):202-207.

35. Mitra P, Zheng X, Czech MP: RNAi-based analysis of CAP, Cbl, and Crkll function in the regulation of GLUT4 by insulin. J Biol Chem 2004, 279(36):37431-37435

36. Morrow IC, Parton RG: Flotillins and the PHB domain protein family: rafts, worms and anaesthetics. Traffic 2005, 6(9):725-740.

37. Chiang SH, Baumann CA, Kanzaki M, Thurmond DC, Watson RT, Neudauer CL, Macara IG, Pessin JE, Saltiel AR: Insulin-stimulated GLUT4 translocation requires the CAP-dependent activation of TC10. Nature 2001, 410(6831):944-948.

38. Fecchi K, Volonte D, Hezel MP, Schmeck K, Galbiati F: Spatial and temporal regulation of GLUT4 translocation by flotillin-1 and caveolin-3 in skeletal muscle cells. FASEB J 2006, 20(6):705-707.

39. Santamaría A, Castellanos E, Gómez V, Benedit P, Renau-Piqueras J, Morote J, Reventós J, Thomson TM, Paciucci R: PTOV1 Enables the Nuclear Translocation and Mitogenic Activity of Flotillin-1, a Major Protein of Lipid Rafts. Mol Cell Biol 2005, 25(5):1900-1911.

40. Gómez V, Sesé M, Santamaría A, Martínez JD, Castellanos E, Soler M, Thomson TM, Paciucci R: Regulation of Aurora B Kinase by the Lipid Raft Protein Flotillin-1. J Biol Chem 2010, 285(27):20683-20690.

41. Langhorst MF, Reuter A, Luxenhofer $G$, Boneberg EM, Legler DF, Plattner $H$, Stuermer CA: Preformed reggie/flotillin caps: stable priming platforms for macrodomain assembly in T cells. FASEB J 2006, 20(6):711-713.

42. Stuermer CA, Langhorst MF, Wiechers MF, Legler DF, von Hanwehr SH, Guse AH, Plattner H: PrPc capping in T cells promotes its association with the lipid raft proteins reggie-1 and reggie-2 and leads to signal transduction. FASEB J 2004, 18(14):1731-1733.

43. Das V, Nal B, Dujeancourt A, Thoulouze MI, Galli T, Roux P, Dautry-Varsat A, Alcover A: Activation-induced polarized recycling targets T cell antigen receptors to the immunological synapse; involvement of SNARE complexes. Immunity 2004, 20(5):577-588.

44. Hazarika P, McCarty MF, Prieto VG, George S, Babu D, Koul D, Bar-Eli M, Duvic M: Up-regulation of Flotillin-2 Is Associated with Melanoma Progression and Modulates Expression of the Thrombin Receptor Protease Activated Receptor 1. Cancer Res 2004, 64(20):7361-7369.

45. Kato N, Nakanishi M, Hirashima N: Flotillin-1 Regulates IgE ReceptorMediated Signaling in Rat Basophilic Leukemia (RBL-2H3) Cells. J Immunol 2006, 177(1):147-154.

46. Kimura A, Baumann CA, Chiang SH, Saltiel AR: The sorbin homology domain: a motif for the targeting of proteins to lipid rafts. Proc Natl Acad Sci USA 2001, 98(16):9098-9103.

47. Wakasugi K, Nakano T, Kitatsuji C, Morishima I: Human neuroglobin interacts with flotillin-1, a lipid raft microdomain-associated protein. Biochem Biophys Res Commun 2004, 318(2):453-460.

48. Langhorst MF, Solis GP, Hannbeck S, Plattner H, Stuermer CA: Linking membrane microdomains to the cytoskeleton: Regulation of the lateral mobility of reggie-1/flotillin-2 by interaction with actin. FEBS Lett 2007, 581(24):4697-4703. 
49. Cornfine S, Himmel M, Kopp P, Azzouzi KEl, Wiesner C, Krüger M, Rudel T, Linder S: The kinesin KIF9 and reggie/flotillin proteins regulate matrix degradation by macrophage podosomes. Mol Biol Cell 2011, 22(2):202-215.

50. Ludwig A, Otto GP, Riento K, Hams E, Fallon PG, Nichols BJ: Flotillin microdomains interact with the cortical cytoskeleton to control uropod formation and neutrophil recruitment. J Cell Biol 2010, 191(4):771-781.

51. Sugawara Y, Nishii H, Takahashi T, Yamauchi J, Mizuno N, Tago K, Itoh H: The lipid raft proteins flotillins/reggies interact with Gaq and are involved in Gq-mediated p38 mitogen-activated protein kinase activation through tyrosine kinase. Cellular Signalling 2007, 19(6):1301-1308

52. Reuter A, Binkle U, Stuermer CA, Plattner H: PrPc and reggies/flotillins are contained in and released via lipid-rich vesicles in Jurkat T cells. Cell Mol Life Sci 2004, 61(16):2092-2099.

53. Pimpinelli F, Lehmann S, Maridonneau-Parini I: The scrapie prion protein is present in flotillin-1-positive vesicles in central- but not peripheralderived neuronal cell lines. Eur J Neurosci 2005, 21(8):2063-2072.

54. Jacobowitz DM, Kallarakal AT: Flotillin-1 in the substantia nigra of the Parkinson brain and a predominant localization in catecholaminergic nerves in the rat brain. Neurotox Res 2004, 6(4):245-257.

55. Rajendran L, Knobloch M, Geiger KD, Dienel S, Nitsch R, Simons K, Konietzko U: Increased Abeta Production Leads to Intracellular Accumulation of Abeta in Flotillin-1-Positive Endosomes. Neurodegener Dis 2007, 4(2-3):164-170

56. Kirsch C, Eckert GP, Mueller WE: Statin effects on cholesterol microdomains in brain plasma membranes. Biochem Pharmacol 2003, 65(5):843-856.

57. Chen WX, Leto D, Chiang SH, Wang Q, Saltiel AR: Activation of RalA is required for insulin-stimulated Glut4 trafficking to the plasma membrane via the exocyst and the motor protein Myo1c. Dev Cell 2007, 13(3):391-404.

58. Solis G, Malaga-Trillo E, Plattner H, Stuermer CA: Cellular roles of the prion protein in association with reggie/flotillin microdomains. Front Bios $i$ 2010, 15:1075-1085.

doi:10.1186/1743-422X-8-479

Cite this article as: Zhao et al.: Research advances on flotillins. Virology Journal 2011 8:479.

\section{Submit your next manuscript to BioMed Central and take full advantage of:}

- Convenient online submission

- Thorough peer review

- No space constraints or color figure charges

- Immediate publication on acceptance

- Inclusion in PubMed, CAS, Scopus and Google Scholar

- Research which is freely available for redistribution

Submit your manuscript at www.biomedcentral.com/submit 